\title{
Bilateral Renal Metastasis of an Inguinal Malignant Solitary Fibrous Tumor, 9 Years after Primary Surgical Treatment
}

\author{
Zafer Demirer $^{\mathrm{a}}$ Murat Zor ${ }^{\mathrm{c}}$ Bulent Kurt $^{\mathrm{b}}$ Yasar Bozkurt ${ }^{\mathrm{a}}$ Ibrahim Yildirim ${ }^{\mathrm{a}}$ \\ Departments of a Urology and ${ }^{\mathrm{b}}$ Pathology, Gulhane Military Medical Academy, Ankara, and ${ }^{\mathrm{c}}$ Department of \\ Urology, Sarikamis Military Hospital, Kars, Turkey
}

\section{Key Words}

Malignant solitary fibrous tumor $\cdot$ Soft tissue $\cdot$ Kidney •

Metastasis, bilateral

\begin{abstract}
Objective: To report the first case of a bilateral renal solitary fibrous tumor (SFT) as a metastasis of an inguinal malignant SFT. Clinical Presentation and Intervention: A 60-year-old male patient with a history of a right inguinal $7 \times 8 \mathrm{~cm}$ soft tissue mass excision 9 years ago was referred to our clinic with abdominal pain. Both physical examination and chest X-ray were normal. Computed tomography revealed bilateral renal tumor. He was successfully treated with left partial and right radical nephrectomy. Histopathological examination showed a metastasis of the previous inguinal SFT. Conclusion: This case showed that although malignant SFT is extremely rare in the urogenital tract, this tumor should be included in the differential diagnosis when identified in the kidneys.
\end{abstract}

Copyright $\odot 2012$ S. Karger AG, Basel

\section{Introduction}

Solitary fibrous tumor (SFT) is a rare spindle cell neoplasm and was first described in 1931 [1]. It frequently arises from the serosal surface especially in the pleural cavity but extrapleural tissues can also be its origin [2]. The etiology is unknown. Immunohistochemical and ultrastructural studies indicate that the cell of origin for SFT is fibroblastic/primitive mesenchymal cells. Although most SFTs are histologically benign and slowgrowing neoplasms with favorable prognoses, there are also malignant SFTs reported in the literature [3-5]. To our knowledge this is the first report of a bilateral case of renal SFT as a metastasis of an inguinal malignant SFT.

\section{Case Report}

A 60-year-old man who presented with abdominal pain of 2 months' duration was referred to our clinic. The patient's physical examination and chest X-ray were normal. He had a history of right inguinal $7 \times 8 \mathrm{~cm}$ soft tissue mass excision 9 years ago. The pathological diagnosis revealed a malignant SFT without any evidence of kidney or other solid organ metastasis. The computed tomography (CT) of the abdomen revealed an exophytic $16 \times$ $9 \times 9.5 \mathrm{~cm}$ heterogeneous solid mass in the middle pole of the right kidney and a $5 \times 4 \times 3.5 \mathrm{~cm}$ solid mass in the lower pole of the left kidney (fig. 1). Blood urea and creatinine levels were in normal ranges. Initially, left partial and latter right radical nephrectomy was performed. Pathological examination revealed a not well-circumscribed mesenchymal tumor. It was composed of hypercellular nodular areas and among them less cellular areas containing dense collagenous bands (fig. 2). Neoplastic cells had small ovoid to spindle-shaped nuclei with indistinct cytoplasm.

\section{KARGER}

Fax +4161306 1234

E-Mail karger@karger.ch

www.karger.com
(C) 2012 S. Karger AG, Basel

1011-7571/12/0216-0585\$38.00/0

Accessible online at:

www.karger.com/mpp
Murat Zor, MD

Department of Urology

Sarikamis Military Hospital

TR-36500 Kars (Turkey)

Tel. +90 312304 5613, E-Mail murat804@yahoo.com 
Fig. 1. Preoperative CT images showing an exophytic $16 \times 9 \times 9.5 \mathrm{~cm}$ heterogeneous solid mass in the middle pole of the right kidney and a $5 \times 4 \times 3.5 \mathrm{~cm}$ solid mass in the lower pole of the left kidney.
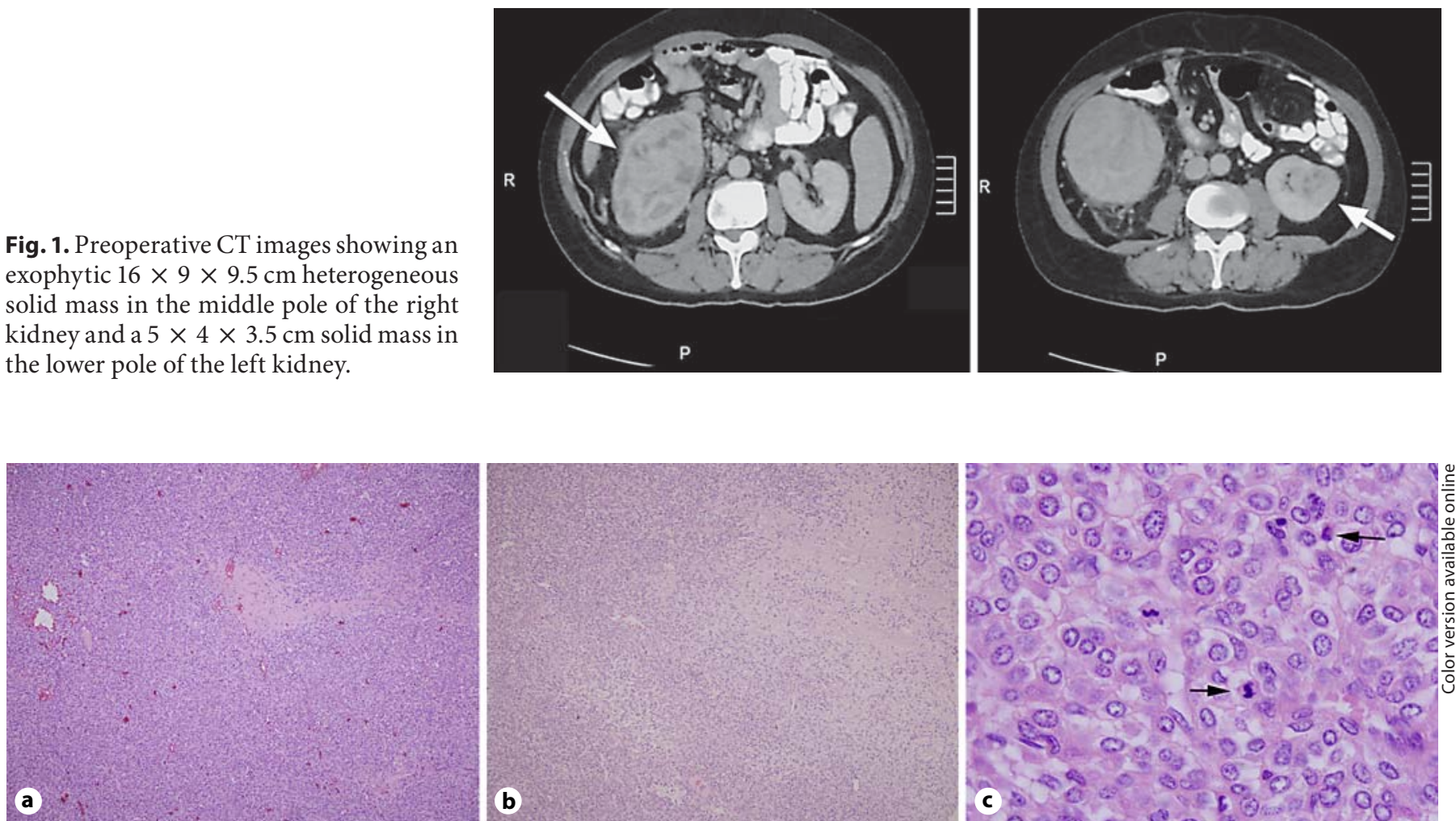

Fig. 2. Histological evaluation revealed hypercellular nodular areas and among them less cellular areas containing dense collagenous bands. a Inguinal mass histology. b Renal mass histology. c Magnified view of mitoses. Arrows show the high mitotic rate.

Tumor cells were interspersed by a stroma including thin-walled vascular spaces. The mitotic rate was high (10-15 mitoses in 10 high-power fields; fig. 2, arrows) and the Ki-67 index was about $10 \%$. There was no necrosis. Neoplastic cells were negative for cytokeratin, SMA, desmin, S100, RCC, CD10, CD31 and CD117. Vimentin, CD34 and CD99 were positive. With these features both tumors were reported as metastasis of previously diagnosed inguinal malignant SFT. One year postoperatively, the patient had no sign of recurrences or any metastasis. He had no complaints. His blood urea was $53 \mathrm{ng} / \mathrm{ml}$ and blood creatinine was $1.9 \mathrm{ng} / \mathrm{ml}$.

\section{Discussion}

SFT is an uncommon soft tissue neoplasm that has been well recognized in the pleura. The tumor is usually described in the literature as a case report or case series. SFTs of the kidney are extremely rare and less than 30 cases were reported in the English literature [4]. One patient was of pediatric age and all others were adults. The most frequent clinical findings were abdominal or flank pain [4]. Only one bilateral benign SFT was reported in the literature [6].
Grossly, the renal SFTs reported in the literature ranged from 2 to $25 \mathrm{~cm}$. In our case the left kidney was involved with a $16-\mathrm{cm}$ and the right kidney with a $5-\mathrm{cm}$ mass. Most of the lesions have a benign appearance, are well circumscribed or pseudoencapsulated, firm, solid and frequently lobular with a gray to white cut surface. On imaging, they present as a well-defined, large, homogeneous and relatively hypovascular mass. Because it is of extraparenchymal origin, a typical cortical claw sign cannot be documented. Intralesional necrosis and cysts are infrequently encountered [7].

Although most cases are benign, the behavior of SFTs is unpredictable. Because of the overlapping of the histological diagnosis of SFT with other soft tissue tumors, its correct and precise pathological characterization necessitates experienced soft tissue pathologists to evaluate the specimen both for a proper diagnosis and for the detection of malignant features. England et al. [8] listed indicators of malignancy as cell density, the number of mitotic figures, cell atypia and the presence of necrosis. VallatDecouvelaere et al. [9] reported local recurrence to be nearly $4.3 \%$ and distant metastasis $6.7 \%$. A more recent 
series of extrapleural SFTs with a long follow-up period reported by Cranshaw et al. [10] showed that extrapleural SFTs behave clinically in a manner similar to high-grade soft tissue sarcoma with relatively high rates of local recurrence (16.2\%) and metastatic spread (8.9\%). Local recurrence or metastasis occurs most often within the first 2 years, while the sites of distant metastasis are most commonly the lung and the liver. There has been no case of metastasis of malignant SFT to the kidney reported to date. There is only one case report regarding malignant SFT of the kidney reported in the literature [5]. The patient was a 76-year-old man with an incidentally diagnosed unilateral renal mass. The patient complained of abdominal pain and was treated with nephrectomy without any complications. Similarly, our patient was an elderly man with abdominal pain. But he had bilateral re- nal lesions and a history of surgical intervention due to malignant inguinal SFT. Surgical excisions of the lesions revealed late-term metastasis of inguinal malignant SFT. Its greatest value was being the first bilateral malignant SFT of the kidney reported in the literature. This is also the first reported case of malignant SFT bilaterally metastatic to the kidney in a long-term period.

\section{Conclusion}

This case showed that, despite SFT mostly being benign, the risk of local recurrence and metastasis is high even in so-called 'benign' tumors after a long period of time. Thus, long-term follow-up is mandatory in such renal lesions.

\section{References}

1 Klemperer P, Rabin CB: Primary neoplasm of the pleura: a report of five cases. Arch Pathol 1931;11:385-412.

-2 Yazaki T, Satoh S, Iizumi T, Umeda T, Yamaguchi Y: Solitary fibrous tumor of renal pelvis. Int J Urol 2001;8:504-508.

- 3 Hanau CA, Miettinen M: Solitary fibrous tumor: histological and immunohistochemical spectrum of benign and malignant variants presenting at different sites. Hum Pathol 1995;26:440-449.

4 Kurt B, Onguru O, Ozcan A, Cicek AF, Basal S, Ors F, Karslıoglu Y, Gunhan O: Solitary fibrous tumor of kidney: a case report with extensive review of the literature. GMJ 2009; $51: 116-121$.
5 Fine SW, McCarthy DM, Chan TY, Epstein JI, Argani P: Malignant solitary fibrous tumor of the kidney: report of a case and comprehensive review of the literature. Arch Pathol Lab Med 2006;130:857-861.

6 Llarena Ibarguren R, Eizaguirre Zarzai B, Lecumberri Castaños D, Padilla Nieva J, Crespo Atín V, Martín Bazaco J, Azurmendi Sastre V, Pertusa Peña C: Bilateral renal solitary fibrous tumor. Arch Esp Urol 2003;56: 835-840.

7 Pedrosa I, Sun MR, Spencer M, Genega EM, Olumi AF, Dewolf WC, Rofsky NM: MR imaging of renal masses: correlation with findings at surgery and pathologic analysis. Radiographics 2008;28:985-1003.
8 England DM, Hochholzer L, McCarthy MJ: Localized benign and malignant fibrous tumors of the pleura. A clinicopathologic review of 223 cases. Am J Surg Pathol 1989;13: 640-658.

-9 Vallat-Decouvelaere AV, Dry SM, Fletcher CD: Atypical and malignant solitary fibrous tumors in extrathoracic locations: evidence of their comparability to intra-thoracic tumors. Am J Surg Pathol 1998;22:1501-1511.

10 Cranshaw IM, Gikas PD, Fisher C, Thway K, Thomas JM, Hayes AJ: Clinical outcomes of extra-thoracic solitary fibrous tumours. Eur J Surg Oncol 2009;35:994-998. 